\title{
Energy efficiency and resilience against increasing temperatures in summer: the use of PCM and cool materials in buildings
}

\author{
Paola Lassandro*, Silvia D. Turi \\ Construction Technologies Institute, Italian National Research Council, v. Paolo Lembo 38/B, \\ Bari, Italy
}

Email: paola.lassandro@itc.cnr.it

\begin{abstract}
Nowadays, it is important to understand how to combine energy efficiency and the point of view of resilience. Regarding buildings, resilience represents the ability to recover from or adapt to an unfavorable condition or event, maintaining their own functionality and performances. This issue has been ignored for several years, especially in building sector, but the impacts of natural hazards and climate change are becoming more and more influential and frequent. Moreover, urban areas are responsible of a great part of global energy consumption and $\mathrm{CO}_{2}$ emissions, in addition to the intensification of greenhouse effect. For this reason, the use of new technologies (PCM and cool materials) for buildings can affect not only indoor microclimate, but also urban environment. Starting from the dynamic simulations of common buildings in South of Italy and then in other hotter Mediterranean climate (Athens, Tunis), the research analyses various typologies of these materials and possible combined applications. The aim of the study is to understand, through a set of proper indicators, how they can contribute to enhance energy performance of buildings and climate resilience in order to face rising temperatures also at neighbourhood level.
\end{abstract}

Keywords: Climate Change Resilience, PCM, Cool Materials, Cooling Energy Saving, Retrofit.

\section{INTRODUCTION}

In recent years, energy performance of buildings is increasing thanks to the development of new materials and technologies. However, the improvement of energy efficiency cannot always imply an enhancement of resilience in relation to an unexpected and/or unpredictable change that can have critical consequences for a system. A building system can be resilient not only if it has the ability to withstand disruption for its resistance but also if it is able to continue its function and to adapt to an unfavorable condition or event [1]. In fact, resilience is a comprehensive concept [2] and it is related to the performance of system complying with expected standards over time, also in uncertain future. This issue has not been considered properly for several years, especially in building sector, but the impacts of natural hazards and climate change are becoming more and more evident. Indeed, the frequency and intensity of certain types of extreme weather events are increasing because of global warming that, according different scenarios, ranges from 1 to $4.5^{\circ} \mathrm{C}$ by 2100 [3]. In Mediterranean Basin, a robust and large warming is projected, with a maximum in the summer season $[4,5]$.

Moreover, owing to copious atmospheric moisture availability and high current temperatures, especially the zones close to Mediterranean Sea are expected to experience the greatest heat stress change. Therefore, the Mediterranean area is very vulnerable to climate change for rising temperatures [6] and it is necessary to identify actions to address these challenges. Due to intense human activities, urban areas are responsible of a great part of global energy consumption and $\mathrm{CO}_{2}$ emissions, in addition to the intensification of greenhouse effect: they can be considered as a major driving force of climate change.

The increase of urban system resilience has to involve its physical, functional, economic and social subsystems. Buildings are an important part of physical subsystem.

The paper aims to investigate how the retrofitting interventions on common existing residential buildings in Mediterranean climate can affect energy performance and resilience both at building and neighborhood level. The houses are the most widespread buildings, and then their upgrading can give a significant contribution in order to decrease temperatures in urban area in summer. As regards strategies for climate change mitigation, the use of appropriate technologies makes possible to pursue these goals. The application of PCMs (Phase change materials) and cool materials can be an opportunity in order to improve not only energy efficiency but also resilience reducing climate change effects. 


\section{PCMS AND COOL MATERIALS IN BUILDING RETROFITTING}

The potential benefits of the use of PCMs [7, 8] and the application of finishing materials with high reflectance $[9,10]$ have been widely studied distinctly but their combination needs further researches in the field of building retrofitting in relation to climate change mitigation strategy. In fact, building enclosure and its performance influence not only the energy efficiency of a building but also the surrounding environment contributing to global warming. Moreover, the buildings have to be well-insulated according to the EU Directive 2010/31/EC, which aims to steer the building sector towards ambitious energy efficiency standards, but that can cause overheating in summer and increase the use of cooling system. This is rising exponentially due to global warming and to the expansion of middle class, which demands better comfort conditions worldwide. In fact, model simulations, performed in the ClimateCost project, have estimated that residential cooling energy demand will increase of 16 Mtoe/year by 2050 and 53 Mtoe/year by 2100 in Europe [11]. Nevertheless, the intensification of air conditioning systems use produces a lot of heat and greenhouse gases that, in addition to climate change and other anthropogenic emissions, contribute to intensify Urban Heat Island (UHI) effect [12]. It consists of a more significant increase in air temperature in urban areas than in surrounding rural ones. This has an important impact on energy consumption and environmental quality of urban area [13] and its vulnerability can increase if buildings are in bad condition or retrofitting interventions are not effective.

The use of PCMs for their adaptive behavior can be investigated in close relation with urban climate effects and city microclimatic conditions. In fact, adaptability is a core concept in resilience because a changing external environment implies uncertainty [14]. PCMs can be considered as a responsive cooling technique that does not consume energy, replacing or reducing the use of air-conditioning systems. PCMs are solutions that can stop the increase of temperatures and the cooling demands and, at the same time, do not enhance the exposure to earthquake risk of buildings because they are lightweight materials. Thermal energy storage with phase change materials can be achieved without the mass. PCMs can absorb or release heat energy thanks to phase change phenomenon (melting and solidification). According to experimental analysis, the heat capacity per unit volume of a PCM medium can be considered 5-14 times more than traditional sensible heat storage materials such as water, masonry or rock [15]. Thanks to their high storage density and latent heat capacity, PCM can shift part of the heating and cooling loads to off-peak temperature hours and can be investigated as a mitigation strategy for overheating in summer.

The most common classification of PCMs is based on their source materials that can be organic (Paraffin, Fatty acids, etc.) inorganic (hydrated salt, molten salt, metal, etc.) and eutectic (organic \& organic, organic \& inorganic, inorganic \& inorganic). Each type presents different advantages and disadvantages in terms of thermal stability, conductivity, costs and so on, but all of them have high latent heat, which is the most significant feature of PCMs [16]. Anyway, bio-based PCMs (organic) are particular interesting because they derived from rapidly renewable plants (refined soy and palm kernel oil) and thus they are biodegradable.
PCMs are characterized also by different melting temperature and latent heat of fusion. Therefore, the choice of the proper PCM has to be based on location, climate data and required comfort in order to really achieve a mitigation effect to heat wave.

While the introduction of PCMs in construction industry is quite new because they have been adopted since the second half of the twentieth century [17], finishing layer with high solar reflectivity (albedo) was largely used also in the past especially in Mediterranean regions, as we can still see in the old center of the cities that maintains their original features [18]. Since in warm and hot climate the cooling demand prevails over the heating one, the use of light colors makes possible the reflection of a considerable part of solar radiation. The amount of heat transmission to indoor environment decreases if albedo and infrared emissivity increase, but different considerations have to be carried out in relation to urban environment. The walls and the finishing layers of existing residential building are usually made of materials with high emissivity (plaster, paints, masonry, concreate...) that is firstly due to their physical characteristics and then to surface condition and temperature. While a high infrared emittance can make roofs good radiators of heat back to the sky [19], especially at night, the vertical building surfaces can irradiate heat into urban canyons, where the infrared radiations can be amplified by multiple reflections between buildings, pavements and street surfaces. These effects are in direct relation to the ratio of height of building to the distance between them and to the sky view factor that are linked to urban morphology [20]. Thus, it is important to drop surface temperature also of facades that receive less solar rays than roof, but have a key role in pedestrian level overheating. Moreover, in order to face the heat wave, it is important to reduce the heat flux with materials with high thermal leg and attenuation.

Hence, it is necessary to study through dynamic simulation the integration of these two strategies based on the increase of reflectance and responsive thermal capacity to evaluate their efficiency to face climate change.

\section{METHODOLOGY AND SIMULATION MODEL}

In order to go beyond the energy efficiency and to address future scenarios of climate change, the key point is the definition of a method to compare different technological solutions. In fact, the use of specific criteria is necessary for the assessment of resilience of existing buildings to climate change.

Firstly, a comparative analysis in summer conditions was carried out on a reference case study located in a typical Mediterranean city in the South of Italy, combining PCMs with various melting temperatures and different albedo solutions. The simulations were performed through the software Design Builder/Energy Plus and the results were analyzed considering different parameters, defined in order to evaluate energy efficiency and resilience level. In particular, according to the proposed approach, the optimal solution was evaluated by means of three main indicators: reduction of Operative Temperature, Cooling Energy Savings and decrease of External Surface Temperature.

The first two indicators have direct impact on indoor microclimate and energy consumption, while they have indirect influence on urban neighborhood, reducing the heat 
rejected by air conditioning. Instead, the last one influences directly on mitigation of urban areas overheating and of urban heat island phenomenon [21].

In order to add a further element of assessment and to test the resilience level of the adopted solutions, the best ones-were simulated also in cities with warmer climate than that of the base case.

In this way, it is possible to take into account how upgraded residential buildings can face the climate change in the Mediterranean Basin. In fact, the increasing temperatures will transform the hot Mediterranean summer into more critical one, according to future scenarios.

Since it is difficult to predict exactly the future evolution of climate, affected by economic, social, technological and environmental factors, the choice of different hotter Mediterranean cities represents an opportunity to verify the behavior of renovated buildings in more adverse actual climate conditions.

\subsection{The reference case study}

Although geometrical and thermo-physical properties of the building envelope change depending on technological characteristics, different period of construction and location, it is possible to consider a schematic representative layout of a common typology of building stock in Mediterranean cities, as a model for simulation and discussion.

It is a three storeys building with an overall height of about $10.5 \mathrm{~m}$. The residential unit is made of two apartments of about $65 \mathrm{~m}^{2}$, with a central common staircase (Figure 1).

The building has three external walls because it is joined to another building like it on the northeast side. This is the worst configuration of row houses in summer conditions.

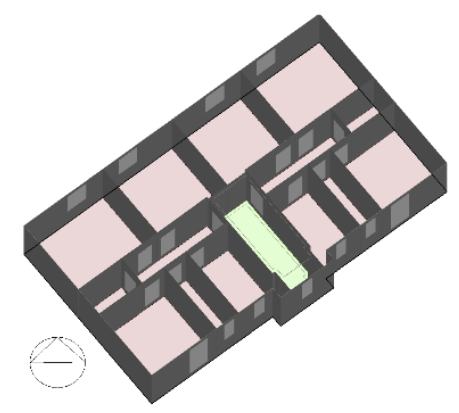

Figure 1. Typical floor of the studied building

The net conditioned area is about $360 \mathrm{~m}^{2}$ and the surface to volume ratio $(\mathrm{S} / \mathrm{V})$ is equal to 0.51 . The gross wall area is of about $577.5 \mathrm{~m}^{2}: 183.75 \mathrm{~m}^{2}$ on southeast side, the same amount on northwest side and $105 \mathrm{~m}^{2}$ on southwest side.

According to typical building techniques of construction after the Second World War, the base case study has reinforced concrete structural frame and cavity wall with hollow bricks, without any insulation layers [22]. The walls and the roof external surfaces have the albedo equal to $40 \%$.

The building was placed in Bari, a city of South of Italy in the Central Mediterranean area, by the sea. It is located in climate zone $\mathrm{C}$ according to the Köppen classification, with hot summer and mild winter. In the last years, increasing temperatures, ongoing climate change and pollution in summer are causing the rise of overheating in this urban area.

The Italian energy standards [23] establish that existing buildings have to reach compulsory thresholds of transmittance in building envelope up to 2021. In particular, it has to be equal to $0.36 \mathrm{~W} / \mathrm{m}^{2} \mathrm{~K}$ for walls and to $0.32 \mathrm{~W} / \mathrm{m}^{2}$ $\mathrm{K}$ for roofs in the climate zone $\mathrm{C}$. Thus, we have improved the considered building, adding polystyrene insulation layer to all the exterior structures. Thus, for vertical walls $\mathrm{U}_{\text {value }}=0.324$ $\mathrm{W} / \mathrm{m}^{2} \mathrm{~K}$ and for roofs $\mathrm{U}_{\text {value }}=0.313 \mathrm{~W} / \mathrm{m}^{2} \mathrm{~K}$.

The window-wall ratio is $7.75 \%: 16.27 \%$ on the Southeast side and $8.1 \%$ on the Northwest one. The windows have aluminum frame and double glazing with an average thermal transmittance of $2.1 \mathrm{~W} / \mathrm{m}^{2} \mathrm{~K}$.

The simulation was carried out considering a standard occupancy profile with four users for each apartment, standing relaxed. For the purpose of this study, only the four hottest months of the year were considered, from $1^{\text {st }}$ June to $30^{\text {th }}$ September.

The dynamic simulation reveals that the building is affected by internal overheating (Figure 2). During the hottest months, the average monthly values of operative temperature are $26.57{ }^{\circ} \mathrm{C}$ and $26.84{ }^{\circ} \mathrm{C}$ respectively in July and August.

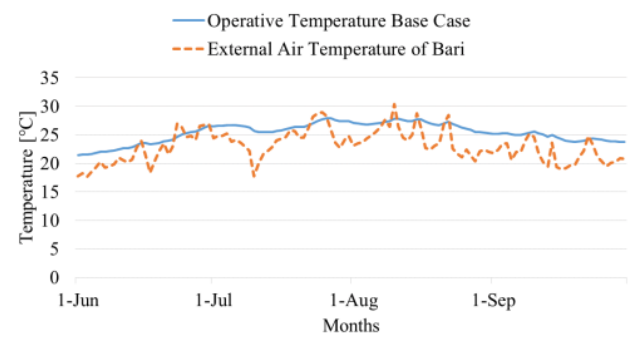

Figure 2. Base case in Bari: trends of temperature during the hottest months

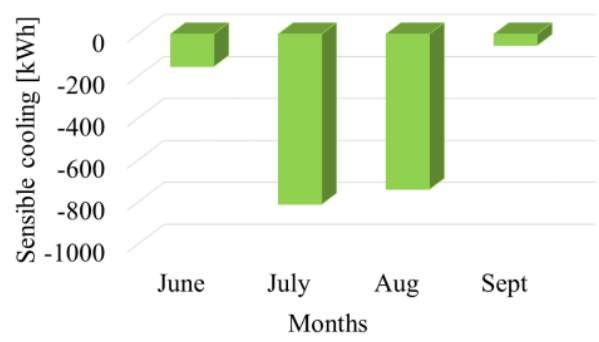

Figure 3. Base case in Bari: sensible cooling during the hottest months

Subsequently, in order to evaluate the cooling energy needs, a cooling system with a COP $=3.5$ was introduced according to Italian Standard [23]. The greatest value of sensible cooling (Figure 3 ) is reached during July $(811.15 \mathrm{kWh})$ and August (739.91 kWh).

The simulation revealed that the building is not efficient to face the hot temperature in summer and the ongoing climate change.

Then, PCMs were used both in walls and roofs as retrofit solution: the selected material is a bio-PCM M91 with latent heat storage capacity of $0.287 \mathrm{kWh} / \mathrm{m}^{2}$, density of $4.9 \mathrm{~kg} / \mathrm{m}^{2}$ and thickness of $3.7 \mathrm{~cm}$ [24]. It was chosen after various simulations, carried out changing the heat storage capacity (M27, M51 and M91). This choice is also confirmed by other previous studies in Mediterranean regions [25].

Subsequently, the set of calculation was performed varying other two main parameters: position (on the external side; in the middle - on the internal surface of the insulation layer; on 
the internal side of building envelope) and melting temperature (Q25, Q27 and Q29).

The Air change rate was fixed equal to $0.9 \mathrm{~h}^{-1}$ according to the UNI TS 11300/2014 -part 1[26], considering a system of micro ventilation, integrated in the windows, and introducing natural night ventilation from 21:00 to 7:00, in order to support the PCM heat discharge.

The second kind of proposed solutions involved the use of cool materials as finishing layers, changing the reflectance of building envelope. Three different albedo (40\%, 65\% and $85 \%)$ were used combined with the tested PCM.

As previously cited in the description of the adopted method, all these configurations were studied in order to evaluate the further improvement of energy efficiency of the building, but also to understand the best solution in the point of view of climate resilience in summer. In fact, these two aspects are not separated, but are strictly linked.

For this reason, the last step was the analysis of the best solution in different climate conditions in order to study the performance of the building in case of increasing temperature. Therefore, the model was tested in two different cities of Mediterranean area, Athens and Tunis, which are characterized by similar distribution, but higher values of temperature, in order to assess the resilient behavior of the solutions.

\section{RESULTS AND DISCUSSION}

Due to the huge amount of calculated data, the analysis focuses only on the PCMs installed on the inner faces of walls and roof, with different melting temperature. This is a good position because it avoids the wide temperature excursions of the exterior surfaces that cause a too fast melting of PCM and reduce positive effect of their use [27]. On the other hand, there are not relevant differences between installation on the inner face of the envelope component and installation in the middle (on the internal face of insulation), but the former is almost equal to the latter (Figure 4). This is also due to the assumed boundary conditions and climate context of simulation.

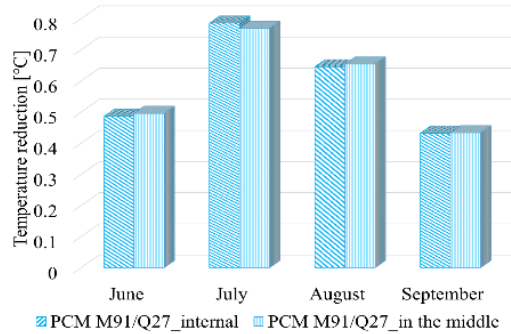

Figure 4. Example of the monthly average reduction of operative temperature, obtained with two different positions of PCM M91/Q27 in the building envelope.

\subsection{Analysis of retrofit solutions with different melting temperature and albedo}

The analysis of the different indicators for each adopted solution provides the possibility to define the optimal one in terms of energy efficiency and resilience.

The results in terms of operative temperature, obtained varying both the melting temperature of PCM and the albedo of external finishing layers, show that the highest values of reduction for all the adopted retrofit solutions respect to the base case is achieved in July (Figure 5).

The PCM with a melting temperature of $25^{\circ} \mathrm{C}$ is the best one along the entire cooling period: this is due to the fact that the average operative temperature of base case ranges from $23.49{ }^{\circ} \mathrm{C}$ in May to $26.84{ }^{\circ} \mathrm{C}$ in August, that are values close to the melting point of the PCM. Moreover, it is easy to see that retrofit solutions behave better in proportion with the increase of the albedo.

However, the greatest monthly average reduction is reached by PCM M91/Q25 with albedo of $85 \%$ in July, during the hottest month in summer: it is equal to $1.73{ }^{\circ} \mathrm{C}$ followed by PCM M91/Q29 and M91/Q27 with albedo of $85 \%$ that achieve both a reduction of about $1.57^{\circ} \mathrm{C}$.

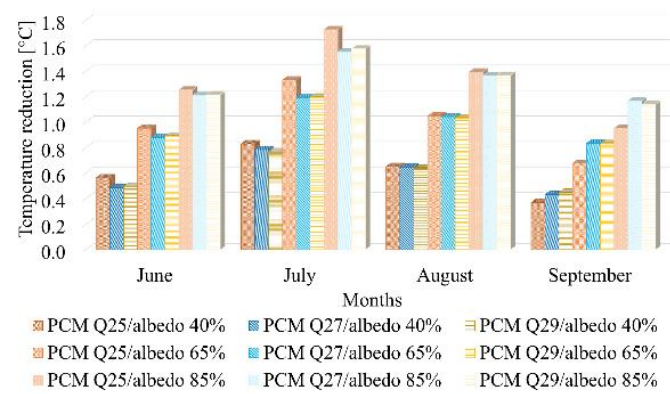

Figure 5. Monthly average reduction of operative temperature in the different retrofit solutions

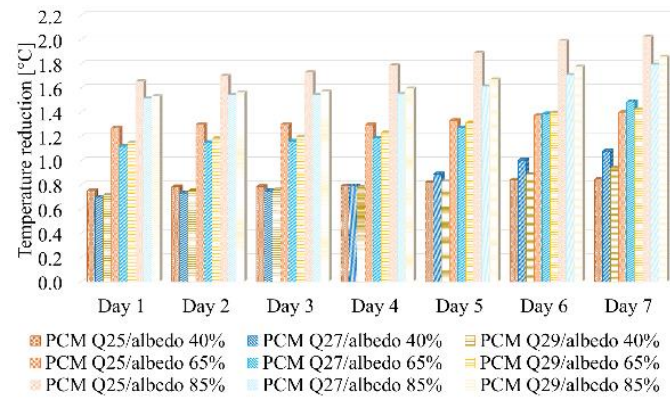

Figure 6. Daily average reduction of operative temperature in different retrofit solutions during the hottest week in Bari

Analyzing in details the reduction of operative temperature in the hottest week of summer in Bari (from $20^{\text {th }}$ to $26^{\text {th }} \mathrm{July}$ ), the Figure 6 confirms the monthly results. It is interesting to highlight that in the hottest days, from Day 5 to Day 7, the best solution without cooling materials ( $40 \%$ albedo) is the PCM M91/Q27, with a cut up to $1.08^{\circ} \mathrm{C}$.

When cooling finishing layers are adopted with an increasing albedo, the internal temperature decreases and promotes the activation of PCM M91/Q25 that prevails on the others. Even in this case the greatest reduction reaches about $2{ }^{\circ} \mathrm{C}$ on $25^{\text {th }}$ and $26^{\text {th }}$ July.

The Figure 7 shows, with reference to $85 \%$ albedo solutions, the trends of operative temperature, the surface inside temperature and the internal one for the building respect to the base case. These profiles are reported for the three hottest days of the week. The building temperature profiles of the refurbished building are always lower than the base case. 


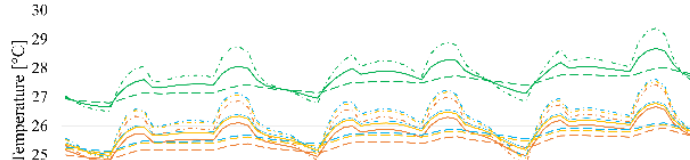

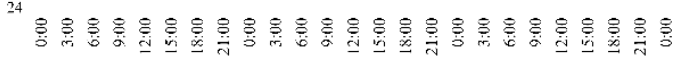

Day PCM M91:Q25 85:in Operulive Tom PCM M11:272 35\% Opcative Tom

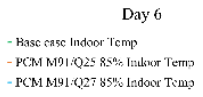

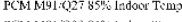

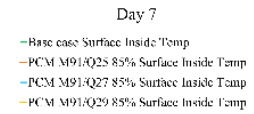

Figure 7. Trends of hourly temperatures in the three hottest days in Bari for the retrofit solutions with $85 \%$ albedo, respect to the base case

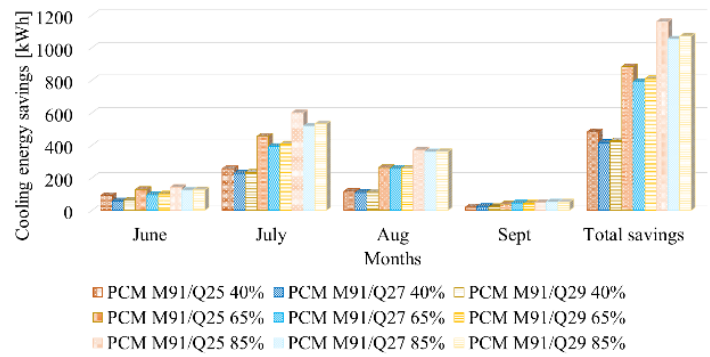

Figure 8. Cooling energy savings in different configurations respect to the base case in summer

As regards sensible cooling, the performance indicator of cooling energy savings is defined as the difference between the cooling energy need of reference case and that of the other retrofit solution. The best results are achieved in July and confirm the trends of Operative Temperature. In particular, the PCM M91/Q25 with 85\% albedo allows to save $600.42 \mathrm{kWh}$ in July, followed by PCM M91/Q29_85\% albedo with 531.15 $\mathrm{kWh}$ and PCM M91/Q27 85\% albedo with $517.15 \mathrm{kWh}$ (Figure 8). Moreover, the total amount of cooling energy savings in the first solution is of $1160.34 \mathrm{kWh}$ in summer (about 66\% less than reference case energy cooling need).

The same considerations could be applied for the hottest week in summer (Figure 9), when the greatest reduction reached by the PCM M91/Q25_85\% albedo is of $84.43 \mathrm{kWh}$ on $20^{\text {th }}$ July (Day 1). This day is not the hottest one of the week and thus the operative temperature keeps constant around $25{ }^{\circ} \mathrm{C}$. Therefore, the PCM with melting temperature $25^{\circ} \mathrm{C}$ and $85 \%$ albedo works very well. However, it remains the best solution for all the days with a reduction of cooling energy need of about $68.60 \%$.

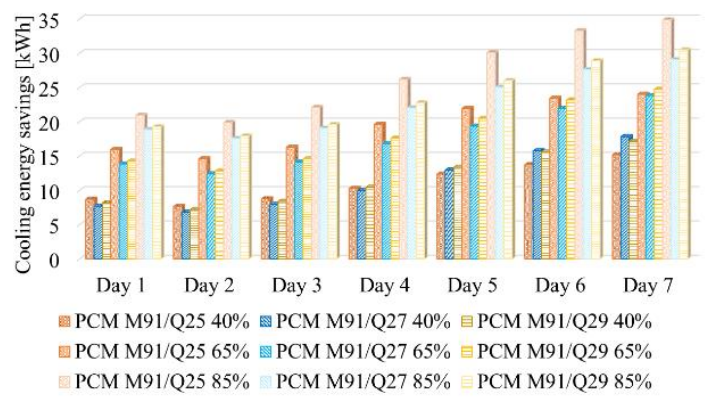

Figure 9. Cooling energy savings in different configurations respect to the base case in the hottest week

The last analyzed performance indicator is very important to verify the influence of this retrofitting actions on the urban surroundings. In fact, the decrease of External Surface Temperature contributes to reduce the Urban Heat Island phenomenon and, the higher the $\mathrm{H} / \mathrm{W}$ ratio, the more significant it is.

Although PCMs influence significantly the indicators of Operative Temperature and Sensible Cooling, they give only a low contribute to the reduction of External Surface Temperature, especially if compared with cool materials strategies. For this reason, the analyzed solution have the PCM in the inner side of the building envelope and rising reflectance in external finishing layers.

The Figure 10 shows the distribution of external surface temperature of walls and roof. The best result in terms of external surface temperature reduction is achieved on southeast wall and roof on $25^{\text {th }}$ July (Day 5).
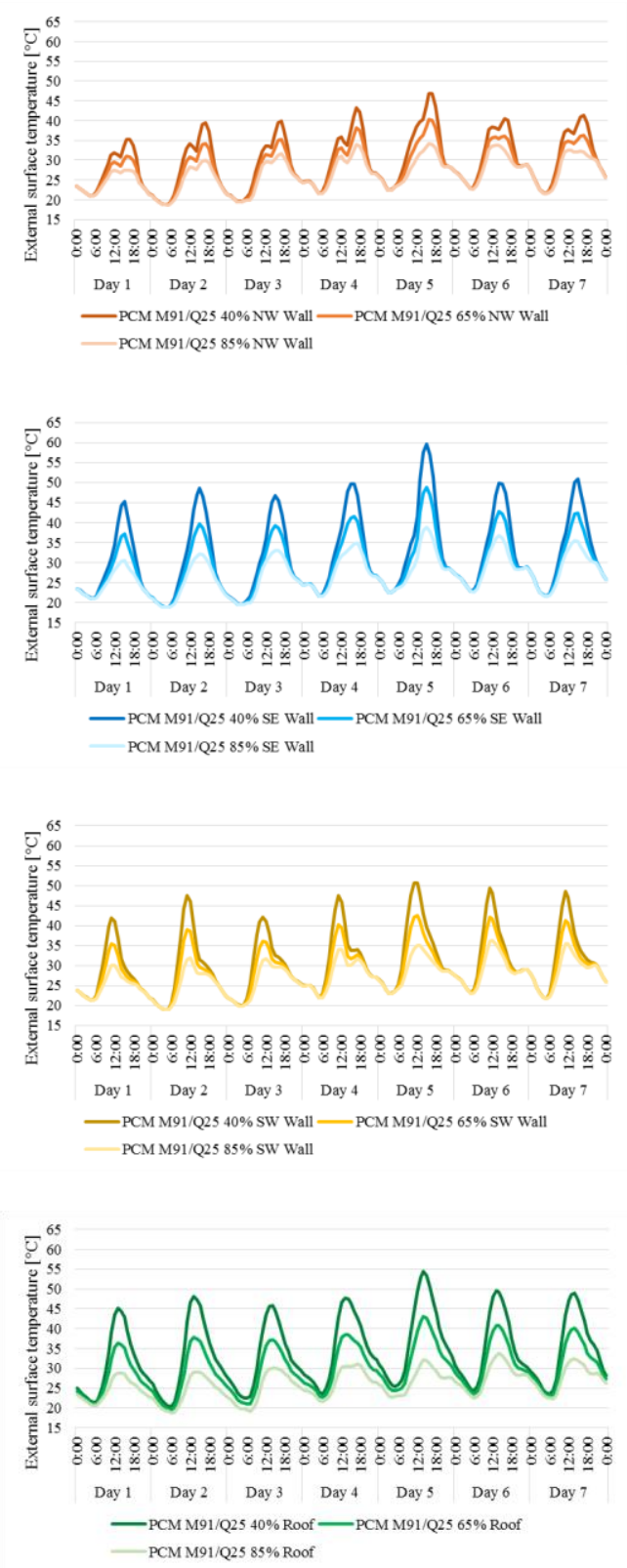

Figure 10. External surface temperature for the PCM M91/Q25 and various albedo during the hottest week: northwest wall, southeast wall, southwest wall and roof

Regarding the southeast wall, the maximum decrease is reached at 3:00 p.m., when the solution with $65 \%$ albedo shows a cut of $10.85{ }^{\circ} \mathrm{C}$ and the solution with $85 \%$ albedo a 
cut of $20.83{ }^{\circ} \mathrm{C}$. Instead, in the roof at 2:00 p.m. there is a reduction of $11.26^{\circ} \mathrm{C}$ for the $65 \%$ albedo and of $22.27{ }^{\circ} \mathrm{C}$ for the $85 \%$ albedo. In the last case, the average reduction of the external surface temperature during all the day is up to $10.50 \%$.

The previous analysis demonstrates that the use of PCMs combined with cool materials guarantees a better performance in cooling season in terms of temperature reduction and cooling energy savings.

The most useful PCM is the M91/Q25 one, but this choice is strictly linked to the climate of Bari.

In order to test furtherly the climate resilience of the different PCMs solutions, the following paragraph analyzes them in other two different cities, characterized by higher external temperatures. Only the best configuration of albedo, fixed to $85 \%$, will be considered and compared with the base case.

\subsection{Analysis of retrofit solutions in different climate conditions}

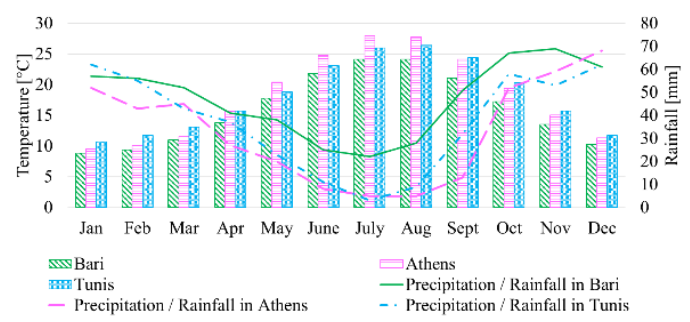

Figure 11. Monthly average air temperature in Bari, Athens and Tunis (https://it.climate-data.org)

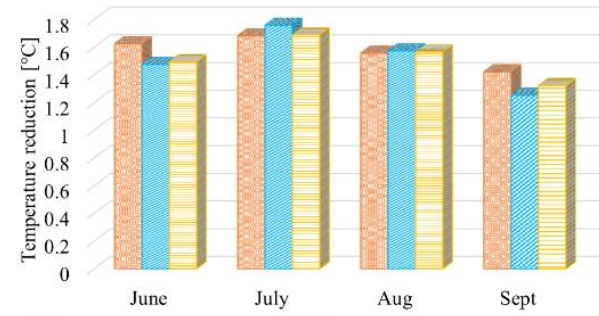

$\square$ PCM Q25/albedo 85\%_Athens $₫$ PCM Q27/albedo 85\%_Athens EPCM Q29/albedo 85\%_Athens

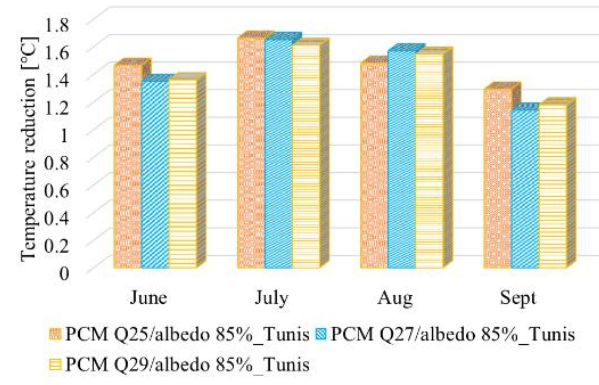

Figure 12. Monthly average reduction of operative temperature obtained with different PCMs in Athens (above) and Tunis (below)

After the analysis of climate data of several Mediterranean cities, the reference residential building was studied in other two different locations, representative of Mediterranean Basin: Athens and Tunis.

The choice of these two cities is not casual: they are located in the same climate zone of Bari, the Csa in Köppen classification, but they are characterized by higher temperature in summer and lower rate of precipitation.

Both Athens and Tunis have hotter summer than Bari, with a temperature trend shifted upwards even if Athens has average temperature values higher than Tunis (Figure 11). For this reason, it is possible hypothesize that in a next future scenario, Bari will go towards similar trends of temperature and precipitations. Moreover, all the three cities are placed near the sea. The average temperature in the year, for both cities, is $18.13{ }^{\circ} \mathrm{C}$, but the warmest month in Athens is July with an average temperature of $27.90{ }^{\circ} \mathrm{C}$, while the warmest month in Tunis is August with $26.40{ }^{\circ} \mathrm{C}$. The maximum reached temperature are $33.30^{\circ} \mathrm{C}$ and $32.40{ }^{\circ} \mathrm{C}$ respectively.

The results obtained by simulations, respect to the base case (40\% albedo and without PCMs) placed in both the cities, are very interesting according to the different analyzed parameters.

As Figure 12 shows, the PCM continues to be worthwhile in terms of Operative Temperature reduction, but while in Bari the PCM M91/Q25 obtained the best result in the hottest month (July), in Athens the reduction obtained by PCM M91/Q27 prevails on the others, with a decrease of $1.76^{\circ} \mathrm{C}$ in July and $1.58^{\circ} \mathrm{C}$ in August. This is due to the highest external temperature in this city. The PCM M91/Q25 has the best performance during the months with lower external temperatures. On the contrary, in Tunis, where the climate conditions are between Bari and Athens meteorological values, the PCMs M91/Q25 and M91/Q27 give similar results in terms of Operative Temperature reduction in July $\left(1.66\right.$ and $1.65{ }^{\circ} \mathrm{C}$ respectively). Instead, in August, during the hottest month, the melting temperature of $27^{\circ} \mathrm{C}$ allows a drop of $1.57^{\circ} \mathrm{C}$, more than the reduction by the PCM M91/Q25 $\left(1.48^{\circ} \mathrm{C}\right)$. In June and September, the melting temperature of $25^{\circ} \mathrm{C}$ is sufficient to guarantee the best performance in terms of temperature.

If the operative temperature reduction in the hottest week in Athens (3-9 $9^{\text {th }}$ August) and Tunis $\left(12^{\text {th }}-18^{\text {th }}\right.$ August) is analyzed in details (Figure 13), the results change furtherly.

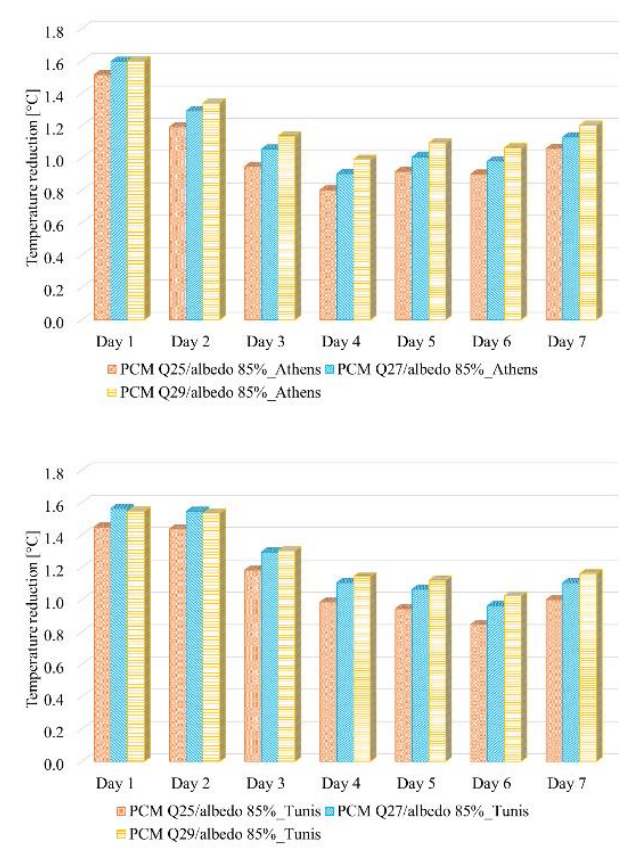

Figure 13. Daily average reduction of operative temperature obtained with different PCMs in Athens (August 3-9) and Tunis (August 12-18) 

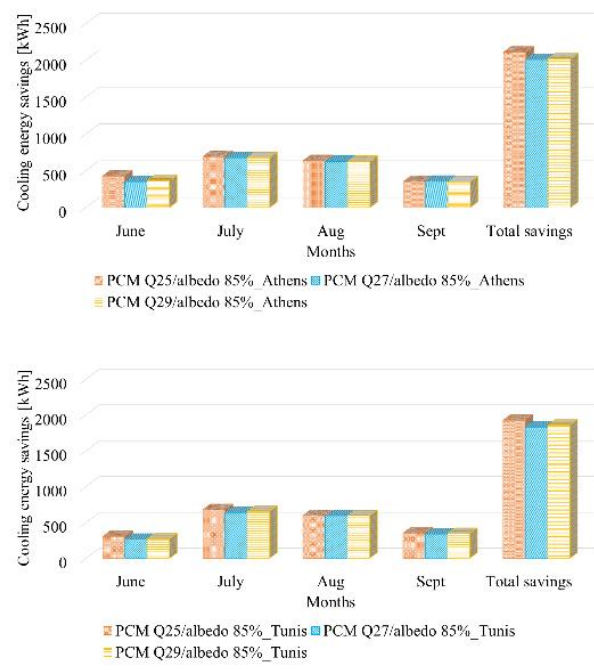

Figure 14. Cooling energy savings in different PCMs solutions in Athens and Tunis in summer

The PCM M91/Q29 becomes the best solution in both cities because of the increasing temperatures that reach their maximum values.

Nevertheless, in all summer, both in Athens and Tunis, the introduction of an ideal cooling system in order to evaluate the sensible cooling demonstrates that the performance of PCM M91/Q25 is still efficient (Figure 14).

In fact, regarding sensible cooling, the three PCMs have similar behavior in the hottest months, but for the entire season, PCM M91/Q25 achieves the best performance with a decrease of about $43 \%$ in terms of sensible cooling in both cities, where the cooling energy need is about twice that of Bari. Instead, in the hottest weeks of the two cities, the PCM M91/Q27 reaches the greatest amount of energy savings, up to $37 \%$ in Athens and up to $36 \%$ Tunis (Figure 15).
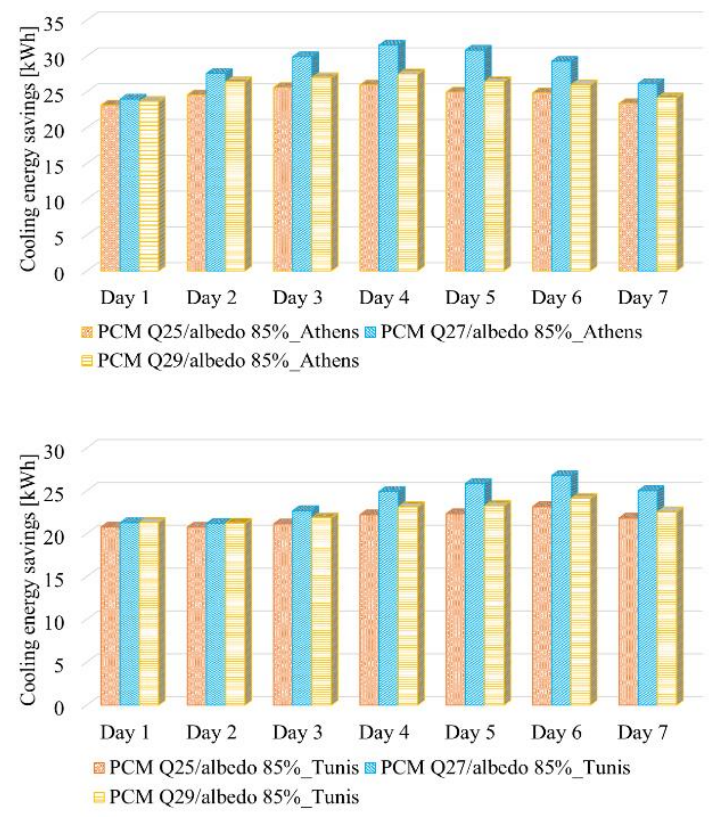

Figure 15. Cooling energy savings in different PCMs solutions in Athens and Tunis in the hottest weeks
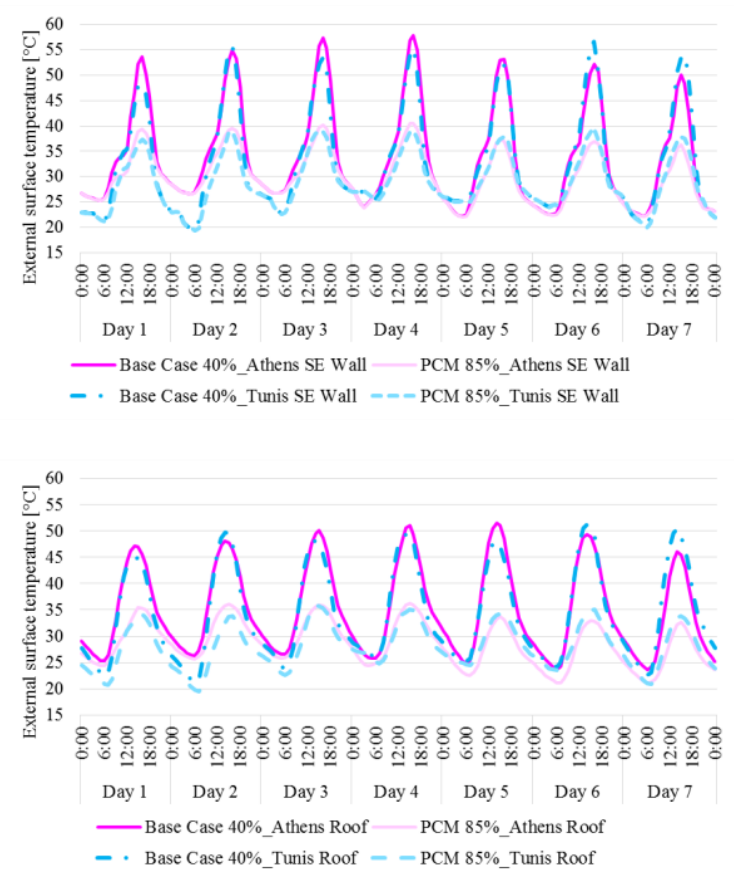

Figure 16. External surface temperature of southeast wall and roof for the PCM M91/Q25 with various albedo during the hottest week, in Athens and Tunis

Finally, in order to complete the analysis, the Figure 16 shows the trends of external surface temperature in the new simulated configuration during the hottest weeks. Even in this case the presence of PCM has not a great influence on this parameter, while the adoption of cool finishing layer with $85 \%$ albedo continues to be efficient.

In Athens, the daily obtained average reduction of the external surface temperature during all the day is up to $4.7 \%$ in the southeast wall and $8.20 \%$ in the roof (Day 5). Instead, in Tunis, it is up to $4.67 \%$ and $6.98 \%$ respectively (Day 2).

\section{CONCLUSIONS}

The research has investigated the improvement of energy efficiency and climate change resilience in residential existing buildings in Mediterranean area through two different retrofitting solutions: PCMs and cool materials.

The applied methodology, based on the identified indicators - reduction of Operative Temperature, Cooling Energy Savings and decrease of External Surface Temperature - have proved to be useful to take into account direct effects on indoor microclimate and energy consumption as well as on the potential infrared radiations through building envelope to outside environment.

The combination of PCMs and cool coatings is very difficult to analyze owing to the interaction of the two strategies that are strictly affected by surrounding climate and boundary conditions. The analysis of the different indicators demonstrates their sensitivity to the integration of the two strategies because they change whether PCMs and cool materials are applied alone or in combination. When, e.g., only the PCM is applied, during the hottest week in Bari the PCM M91/Q27 gives the best results (e.g. daily reduction of Operative Temperature up to $1.08^{\circ} \mathrm{C}$ ); instead, combined with cool finishing layers, the best one is the PCM M91/Q25, with a minor melting temperature (e.g. daily reduction of Operative 
Temperature up to $2^{\circ} \mathrm{C}$ ). PCM absorbs the heat that the cool finishing layer is not able to reflect and that passes through envelope by conduction.

Moreover, another factor that influences the assessment of these actions is the period of evaluation. If we consider only the hottest week with maximum temperature values, the performance of PCM with higher melting temperatures are slightly better than the other ones. This advantage is lost in the long period due to the variability of temperature during the whole summer that makes PCM M91/Q25, with lower melting temperature, more effective (monthly average reduction of operative temperature equal to $1.73^{\circ} \mathrm{C}$; energy cooling saving of $66 \%$; daily external surface temperature reduction up to $10.50 \%$ ). The combined rising reflectance of the external surfaces enhances this behavior and improves the building energy performance in the whole period, reducing the external surface temperature.

The simulations in Athens and Tunis demonstrated that the PCM M91/Q25 with 85\% albedo remains the most effective solution also in hotter climate conditions, thanks to the adaptive behavior of PCM, which interact with weather change, and to the capacity of high reflectance layers to mitigate the high solar radiation typical of the Mediterranean area. The PCM M91/Q25 allows the greatest savings of energy cooling (energy cooling saving of $43 \%$ in both cities) and the major drop of temperatures (reduction of operative temperature up to $1.76^{\circ} \mathrm{C}$ for Athens and $1.66{ }^{\circ} \mathrm{C}$ for Tunis; daily external surface temperature reduction up to $8.20 \%$ for Tunis and up to $6.98 \%$ for Athens). This highlights that the adopted combined strategies, in relation to the identified indicators, are also worthwhile and resilient in relation to ongoing climate change and global warming.

\section{REFERENCES}

[1] Zhou H., Wang J., Wan J., Jia H. (2010). Resilience to natural hazards: a geographic perspective, Natural Hazards, Vol. 53, No. 1, pp. 21-41. DOI: 10.1007/s11069-009-9407-y

[2] Achour N., Pantzartzis E., Pascale F., Price A.D.F. (2015). Integration of resilience and sustainability: from theory to application, Int $J$ Disaster Resilience in the Built Environment, Vol. 6, No. 3, pp. 347-362. DOI: 10.1108/IJDRBE-05-2013-0016

[3] Nazarenko L., Schmidt G.A., Miller R.L., Tausnev N., et al. (2015). Future climate change under RCP emission scenarios with GISS Modele 2, J. Advances in Modeling Earth Systems, Vol. 7, pp. 244-267. DOI: 10.1002/2014MS000403

[4] Stocker T.F., Qin D., Plattner G.K., Tignor M., et al. (2013). Climate change 2013: the physical science basis. contribution of working group I to the fifth assessment report of the IPCC, Cambridge University Press, Cambridge, United Kingdom and New York, USA. DOI: $10.1017 / \mathrm{CBO} 9781107415324$

[5] Giorgi F., Lionello P. (2008). Climate change projections for the Mediterranean region, Global Planet. Change, Vol. 63, pp. 90-104. DOI: 10.1016/j.gloplacha.2007.09.005

[6] Ozturk T., Ceber Z.P., Türkeş M., Kurnaz M.L. (2015). Projections of climate change in the Mediterranean Basin by using downscaled global climate model outputs, Int. J. Climatol., Vol. 35, pp. 4276-4292. DOI: 10.1002/joc. 4285

[7] Akeiber H., Nejat P., Majid M.Z.A., Wahid M.A., Jomehzadeh F., Famileh I.Z., Calautit J.K., Hughes B.R. (2016). A review on phase change material (PCM) for sustainable passive cooling in building envelopes, Renewable and Sustainable Energy Reviews, Vol. 60, pp. 1470-1497. DOI: $10.1016 /$ j.rser.2016.03.036

[8] Souayfane F., Fardoun F., Biwole P.H. (2016). Phase change materials (PCM) for cooling applications in buildings: A review, Energy and Buildings, Vol. 129, pp. 396-431. DOI: 10.1016/j.enbuild.2016.04.006

[9] Zinzi M. (2016). Exploring the potentialities of cool facades to improve the thermal response of Mediterranean residential buildings, Solar Energy, Vol. 135, pp. 386-397. DOI: 10.1016/j.solener.2016.06.021

[10] Lassandro P., Cosola T. (2016). Innovative flat roof solutions for existing buildings: from energy efficiency to impacts mitigation, Proceeding of the 41st IAHS World Congress on Sustainability and Innovation for the Future, Albufeira, Portugal.

[11] Mima S., Criqui P. (2015). The costs of climate change for the European energy system, an assessment with the POLES Model, Environmental Modeling \& Assessment, Vol. 20, No. 4, pp. 303-19. DOI: $\underline{10.1007 / \mathrm{s} 10666-015-9449-3}$

[12] Levermore G., Parkinson J., Lee K., Laycock P., Lindley S. (2017). The increasing trend of the urban heat island intensity, Urban Climate, DOI: $\underline{\text { 10.1016/j.uclim.2017.02.004 }}$

[13] Santamouris M. (2014). On the energy impact of urban heat island and global warming on buildings, Energy and Buildings, Vol. 82, pp. 100-113. DOI: 10.1016/j.enbuild.2014.07.022.

[14] Carmichael D.G. (2015). Incorporating resilience through adaptability and flexibility, Civil Engineering and Environmental Systems, Vol. 32, No. 1-2, pp. 3143. DOI: $\underline{10.1080 / 10286608.2015 .1016921}$

[15] Cammarata G., Monaco L., Cammarata L., Petrone G. (2013). A numerical procedure for PCM thermal storage design in solar plants, International Journal of Heat and Technology, Vol. 31, No. 2, pp. 105-110. DOI: 10.18280/ijht.310214

[16] Abuzaid A.I., Reichard G. (2016). An assessment of utilizing Phase Change Materials (PCM) towards energy performance in building enclosures, in $3 \mathrm{rd}$ Residential Building Design \& Construction Conference, Penn State, University Park.

[17] Harland A., MacKay C., Vale B. (2010). Phase change materials in architecture, Victoria University of Wellington, New Zealand.

[18] Akbari H., Kolokotsa D. (2013). Three decades of urban heat islands and mitigation technologies research, Energy and Buildings, Vol. 133, pp. 834-842. DOI: $\underline{10.1016 / j . e n b u i l d .2016 .09 .067}$

[19] Al-Obaidi K.M., Ismail M., Abdul Rahman A.M. (2014). Passive cooling techniques through reflective and radiative roofs in tropical houses in Southeast Asia: A literature review, Frontiers of Architectural Research, Vol. 3, No. 3, pp. 283-297. DOI: 10.1016/j.foar.2014.06.002

[20] Delmastro C., Mutani G., Schranz L., Vicentini G. (2015). The role of urban form and socio-economic variables for estimating the building energy savings 
potential at the urban scale, International Journal of Heat and Technology, Vol. 33, No. 4, pp. 91-100. DOI: 10.18280/ijht.330412

[21] Lassandro P., Di T.S. (2017). Façade retrofitting: from energy efficiency to climate change mitigation, 50th International Conference Beyond NZEB Buildings.

[22] Di T.S., Stefanizzi P. (2015). Energy analysis and refurbishment proposals for public housing in the city of Bari, Italy, Energy Policy, Vol. 79, pp. 58-71. DOI: 10.1016/j.enpol.2015.01.016

[23] Italian Republic Decree of the Ministry of Economic Development Applicazione delle metodologie di calcolo delle prestazioni energetiche e definizione delle prescrizioni e dei requisiti minimi degli edifici. (2015). D.M. 26/06/2015 - Annex 1B.
[24] Phase Change Energy Solutions, Products. (2017). from http://www.phasechange.com.au, accessed on 01 May 2017.

[25] Panayiotou G.P., Kalogirou S.A., Tassou S.A. (2016). Evaluation of the application of Phase Change Materials (PCM) on the envelope of a typical dwelling in the Mediterranean region, Renewable Energy, Vol. 97, pp. 24-32. DOI: 10.1016/j.renene.2016.05.043

[26] UNI/TS 11300 - Energy performance of buildings, Part 1: Evaluation of energy need for space heating and cooling (2014). UNI/TS 11300/2014-1.

[27] Ascione F., Bianco N., De Masi R.F., de Rossi F., Vanoli G.P. (2014). Energy refurbishment of existing buildings through the use of phase change materials: energy savings and indoor comfort in the cooling seasons, Applied Energy, Vol. 111, pp. 990-1007. DOI: $\underline{10.1016 / \text { j.apenergy.2013.08.045 }}$ 